\title{
Toward an epigenetic view of our musical mind
}

\section{Claudio Brigati ${ }^{1}{ }^{*}$, Maria Cristina Saccuman ${ }^{2}$, Barbara Banelli ${ }^{1}$, Angela Di Vinci ${ }^{1}$, Ida Casciano ${ }^{1}$, Luana Borzi ${ }^{1}$, Alessandra Forlani ${ }^{1}$, Giorgio Allemanni ${ }^{1}$ and Massimo Romani ${ }^{1}$}

Laboratory of Tumor Genetics, National Cancer Institute, Genova, Italy

${ }^{2}$ Divisione di Neuroscienze, Istituto San Raffaele, Università Vita-Salute, Milano, Italy

\section{Edited by:}

Berit Kerner, University of California Los Angeles, USA

\section{Reviewed by:}

Terrie Vasilopoulos, University of

Chicago, USA

Susan Carnell, Columbia University

College of Physicians and Surgeons, USA

${ }^{*}$ Correspondence:

Claudio Brigati, National Cancer

Institute, Largo Benzi 10, 16132

Genova, Italy

e-mail: claudio.brigati@istge.it
We are transient beings, in a world of constantly changing culture. At home in the fields of Art and Science, seemingly capable of magnificent abstractions, humans have an intense need to externalize their insights. Music is an art and a highly transmissible cultural product, but we still have an incomplete understanding of how our musical experience shapes and is vividly retained within our brain, and how it affects our behavior. However, the developing field of social epigenetics is now helping us to describe how communication and emotion, prime hallmarks of music, can be linked to a transmissible, biochemical change.

Keywords: music, epigenetics

\section{A PREMISE AND SOME QUESTIONS}

In 1986, Susumu Ohno published a work based on the following tenet: all music has held on the repetition of small replicating units, obsessively used by great musicians forced to plagiarize themselves, thus being easily recognizable. Similar units are found in our genetic code (Ohno and Ohno, 1986). Ohno's observations reinforce the notion that biological and cultural evolution, albeit with different speed, share similar mechanisms. Exploring such mechanisms could provide an approach to Ohno's observation that some repeating units of artistic creations are "forced" to reiterate, sometimes becoming the signature of an artist for generations to come.

But what is a creative product of the mind? An unwilling representation of the outside physical world? (Custers and Aarts, 2010). Something that emerges, almost magically, from our past experience? Is it a specific kind of action? Can our behavior, even the most ineffable (such as music our focus here) have a "genetic" and neural blueprint?

\section{ENVIRONMENT - THE BRAIN THAT FOLLOWS, AND AN EPIGENETIC NEURONAL MEMORY}

In the past decade, it has been shown that neurogenesis continues in adults, and is related to the amount of cognitive and physical stimulation to which the animal is exposed. For example, rats placed in an enriched environment, where social interaction with other rats was possible, were found to have increased neurogenesis compared to rats placed in individual cages (Gould et al., 1999). Adult neurogenesis has also been observed in primates. Indeed, it appears that about $40 \%$ of granule cells in the macaque dentate gyrus are added post-natally. Cell proliferation and neurogenesis peak during the first year, but continue to significant levels in mature monkeys (Jabes et al., 2010). In humans, neurogenesis is now thought to proceed for the entire life of individuals, if proper stimulation is available (Kuzumaki et al., 2011). Music can be such a stimulus.
Music has been an important part of human history, in all cultures. Phylogenetically, it seems likely that music has played a role in language evolution, and in supporting social functions with important evolutionary roles, such as group cohesion and communication. Making music, especially in a group, is a demanding, multi-modal task that engages the brain on many different levels, from auditory feature extraction and integration to auditory Gestalt formation, syntactic processing, learning, memory, social cognition, and action (Koelsch, 2005a,b; Koelsch et al., 2005). With the demands it places on the nervous system, musical training promotes brain plasticity, resulting in functional and structural changes. Neuroanatomical differences between musicians and non-musicians have been reported in the corpus callosum, and in motor, auditor, and visuospatial regions, including the precentral gyrus and the planum temporale. Changes in functional representations have been observed in somatosensory and auditory regions in musicians (Wan and Schlaug, 2010). Recent work by Kraus using EEG suggests that musically trained individuals might be better at encoding speech sounds (Patel, 2008). These effects are more marked in musicians who had started training in early childhood, but a few studies show that intense musical training can be effective through the lifespan, protecting the aging brain from cognitive decay (Wan and Schlaug, 2010). From a neurobiological and cognitive perspective, neural plastic changes, promoted by music fruition and training, are processes known as long-term potentiation (LTP) consisting essentially of remodeling through strengthening of existing synaptic connections. Indeed, in contextual memories, synapses are of different strength and duration depending on a number of factors, including the emotional component of a largely sensory input. The Hebbian rule "fire together, wire together" applies mostly to affective or arousal situations accompanying an event, so that neurons from different areas are simultaneously activated and will later fire together, once a new equivalent input occurs. Activation and transcription of several genes involved in excitability, transmitter release and 
the maintenance of transmembrane potential is responsible for neuronal activity and LTP. Transcriptional activity, however, is preceded by structural changes of chromatin in a given set of loci and such "epigenetic" modifications must be taken into account when dealing with all cells, including neurons.

Epigenetics describes the way gene expression can change stably and be transmitted to subsequent cellular generations without modifications of the underlying coding sequence. This is achieved via the action of DNA and histone-modifying enzymes. Epigenetic changes can operate rapidly and on large fractions of the genome; they can be promptly reversible but also stable and long lasting. They can take the form of a self-sustaining and progressively strengthening feed-back loops (Krupanidhi et al., 2009). Such transcriptional-translational loops are important in a variety of situations, including circadian clock oscillators (Bellet and Sassone-Corsi, 2010).

Epigenetics is an ideal way for a fixed code to cope quickly, reversibly, and on a long range with abrupt environmental changes. In the "environmental epigenetics" hypothesis, external (including social) events can remodel the epigenome, leading to sustained alterations in its structure, delimiting transcription factoraccessible regions, and eventually generating stable effects on gene transcription (Ohta et al., 2002; Branchi, 2009; Leshem and Schulkin, 2011). Acquired epigenetic characteristics may be then transmitted both to the mitotic progeny, accounting for cell memory, and, if occurring in a proper developmental window, to subsequent generations (Leshem and Schulkin, 2011; Gilbert et al., 2012). Could such mechanisms work on largely resting, post-mitotic cells such as neurons? Could external factors epigenetically shape our brain? And on what mechanistic basis?

Rapidly accumulating evidence suggests that the adult nervous system has co-opted the same epigenetic mechanisms used to ensure cellular memory as a major tool for neural information storage, that is brain memory (Levenson et al., 2004; Levenson and Sweatt, 2005). On a molecular basis, despite many new mechanisms such as non-coding RNA (Mehler and Mattick, 2007) and prion multimerization (Si et al., 2003) have been found active in the CNS and could play a role in neuronal memory (Brown and Mastrianni, 2010) major focus is currently held on histone acetylation and the CREB/CBP system, crucial to LTP, the molecular foundation of learning and memory. For instance, HAT activity of CREB binding protein (CBP) appears critical in both long-term facilitation in Aplysia and the formation of long-term memory in rodents (Levine et al., 2005). In the hippocampus, following activation of NMDA receptors and extracellular signal-regulated kinase (essential events in several forms of LTP) acetylation and phosphorylation of histone H3 are increased (Reul et al., 2009). Accordingly, artificial histone acetylation using histone deacetylase (HDAC) inhibitors such as TSA or SAHA enhances induction of LTP and, importantly, the activity of the BDNF gene, a gene that promotes neurogenesis and new synaptic connections between hippocampal neurons, resulting in reinforced and expanded behavioral memory. Accordingly, old mice, compared with juveniles, exhibit reduced histone acetylation and diminished activation of learning-related genes in the hippocampus. As in the Alzheimer's mice, drugs that boosted histone acetylation improved the older mice's performance on tests of rodent cognition (Lubin, 2011).

DNA methylation also appears to be important in memory consolidation via gene-specific control of transcription, and recent studies have implicated misregulation of DNA methylation in cognitive disorders such as schizophrenia, Rett syndrome, and Fragile $\times$ mental retardation (Lubin, 2011). Interestingly, as stated above, musical training can strongly protect the aging brain from a cognitive decay, somehow paralleling the epigenetic drug treatments described in experimental models. This leads to speculate that music - at least as a learning process would presumably be capable of inducing long lasting chromatin changes, from infancy to adulthood.

\section{A FAMILY PORTRAIT: SOCIAL EPIGENETICS, AFFECTION, AND A MUSIC SAGA}

As stated above, a rich social environment is beneficial to cognitive functions, and a major molecular gear through which the environment could modify the brain is epigenetics. In rodents, early environment is mainly primed by the mother, both through nutritional and behavioral investment. Observations of mother-infant interactions in rodents during the first week postpartum show stable natural variations in maternal behavior, particularly in licking/grooming ( $\mathrm{L}-\mathrm{G}$ ) and arched-back nursing (Champagne et al., 2006, 2007). These differences are a major determinant of the stress response of offsprings later in life (Barha et al., 2007; Champagne and Meaney, 2007; Menard and Hakvoort, 2007). Thus, offsprings born to mothers who exhibit high levels of $\mathrm{L}-\mathrm{G}$ are less anxious in a novel environment and show a reduced steroid response to stress compared with offspring of low-L-G mothers. Cross-fostering studies confirm that these phenotypes are indeed mediated by variations in maternal care received during the early postpartum period (Barros et al., 2006). At the molecular level, stress responses have been associated with the estrogen and glucocorticoid receptors' expression in the brain of the pups (Champagne et al., 2006). Importantly, in offsprings of high and low-L-G mothers the promoters of these receptors show differential, albeit small, epigenetic modifications (Szyf et al., 2005; Weaver, 2007). Of note, offsprings in subsequent generations seem to maintain the phenotype, indicating a putative vertical transmission of the trait in these animals (Champagne and Meaney, 2007; Guerrero-Bosagna et al., 2010). The ability to pass such epigenetic information to the progeny may appear a far-fetched concept, given the diffuse erasing of epigenetic marks during gametogenesis (Hajkova et al., 2008) but it could well result from incomplete genome reprogramming (Rakyan et al., 2003) and may underscore an important evolutionary pressure (Molaro et al., 2011).

Correlative evidence is gathering that epigenetic modifications might occur also in humans as a response to parent-offspring interactions, which in this case are obviously far more complex than in rodents. For example, early life stress coincides with abnormal expression of the serotonin transporter gene (Caspi et al., 2003). Moreover, childhood abuse associates with an increase in pituitary ACTH responses to stress (Rinne et al., 2002) and increased methylation of the BDNF promoter and NRC3 promoter in the hippocampus has been found in suicide victims (McGowan et al., 2009); it would be interesting to investigate if similar 
modifications occur in a variety of other mistreatments, including child neglect with oxytocin/vasopressin deficiency (Carter, 2005). For obvious reasons inherent with studies in humans brains which suffer the severe limitation of being applicable essentially on postmortem subjects the formal demonstration of socially driven epigenetic changes on our species is still far ahead. This is despite the sensitive methods available: for instance, combining immunoprecipitation of methylated DNA with hybridization to tiled promoter arrays (MeDIP-CHIP) or next generation sequencing (MeDIPSeq) allows identification of relevant methylated sequences in virtually any biological material, on a genomic scale, and without relying on a gene-candidate approach (Jacinto et al., 2008). Thus, unless one could demonstrate that epigenetic changes reflecting brain activity can be detectable on peripheral tissues (as postulated for white blood cells, see also Takao et al., 1993) perhaps we should wait further development of neuroimaging, a field improving at a great pace, and allowing studies on living subjects. Although these techniques are currently detecting solely neural activity, expectation is that in a near future they will be capable of revealing also epigenetic changes, at a high resolution. One breakthrough could be for instance to identify such modifications in an indirect way, as epigenetic proteins in action, if the removal or adding marks causes local release of detectable by-products (this is currently one way to detect in vitro histone demethylase LSD1's activity Huang et al., 2007).

As a cultural product, music has a special status. Despite the complexity of the cognitive operations implied by music perception, it seems that newborns and young infants are predisposed to perceive music. From the first days of life, music appears to play an important role for emotional, cognitive, and social development, and infants are surprisingly skilled at processing subtle aspects of musical stimuli (Trehub, 2003). Recently, we have shown that a few hours after birth, infants process music specifically, with a pattern of activation similar to what is observed in adults, and are sensitive to subtle structural alterations in the musical stimuli (Perani et al., 2010). Some components of our music processing skills might be genetically determined (Hose et al., 1987) although this issue is somewhat controversial: on one hand, absolute pitch recognition seems to be heritable (Drayna et al., 2001); however, the gene(s) responsible for deficits in pitch discrimination (Amusia) or Williams disease, both claimed to be transmitted via mendelian heritage (Morris and Mervis, 2000) have never been identified.

Music is also special among social activities, as it couples a message with emotions; this in turn facilitates spreading simply by imitation and self-recognition. Accordingly, emotions, especially early in life, are known to enhance learning, via serotonin-mediated modifications of glutamate receptors, the molecules responsible for plastic changes in synaptic transmission underlying learning (Xu et al., 2007). Indeed, GluR are abundantly expressed and activated by emotion, and their phosphorylation via norepinephrine (NE) lowers the threshold for synaptic incorporation during LTP in hippocampal neurons (Hu et al., 2007). Moreover, maternal care can induce thyroid hormone-dependent serotonin in the pups, and this in turn can trigger the cAMP/PKA pathway (Arnsten et al., 2005) leading to strong HAT activity (Kuo and Allis, 1998; Szyf et al., 2007) and we have already mentioned above the role of other molecules and transmitters (Guan et al., 2002; Hu et al., 2007; Liu et al., 2008). Interestingly, mother's voice, but not irrelevant voices, can protect from dopamine D1 and 5-HT1 receptors' upregulation in the anterior cingulate cortex, as it can occur in stressful conditions (Ziabreva et al., 2003). Even in presocial species, mother's voice can suppress the upregulation of the NMDA receptor NR2B occurring after separation (Ziabreva et al., 2000) and NR2B is heavily epigenetically regulated by methylation (Kim et al., 2006; Tamura et al., 2011).

\section{MUSIC REMAINS}

Music is a universal component of human societies, helping community cohesion (rituals) and mother-child interactions, shaping offspring behavior (Chang et al., 2003). However, music should not be considered an entirely abstract exercise of the mind, being more a synesthetic object. As a tool that modulates affect and promotes the growth of emotional attachment, music might share some features with the L-G-tactile care seen naturally in the animal world, and it could bear all the crucial ingredients to determine an epigenetic change in the brain. Such changes could occur in many areas in the cortex, known to contribute to music fruition (Edeline, 1999) including the medial prefrontal cortex (Janata, 2009) and even the primary auditory cortex (Irvine and Rajan, 1996).

The notions and the literature cited so far about maternal care and gene expression in experimental animals bring us directly to the provoking parallel with the maternal care scenario seen in our species (Figure 1). Within this exemplar framework, could an early musical input be a human counterpart of the pure sensory and tactile stimuli, like L-G? By a "Hebbian" approach, here we see brain sculpture in action, chants, and melodies from a mother forging synapses in an ecstatic infant hearing a motherese-tuned lullaby. Within a standard cognitive framework, crucial genes participating to cell proliferation or synaptic strengthening should be activated in these neurons, and this process underlies specific epigenetic modifications, such as promoter $\mathrm{CpG}$ demethylation (Borrelli et al., 2008). From such repertoire, an action can later be retrieved, after an appropriate environmental input. Epigenetic marks are known to be stably transmitted to daughter cells, constituting the mechanism of cellular memory in many tissues. However, being neurons mainly post-mitotic cells, how would DNA demethylation be accomplished in the brain? Possible candidates could be arasing enzymes, such as demethylases. These recently discovered factors could actively remove repressive methyl marks even in resting cells and are thought to play a pivotal role in development (Eilertsen et al., 2007). A word of caution is necessary, though, since the actual in vivo role and relevance of such proteins has been questioned (see Buchen, 2010, and references therein). Of course, how can an external "social" (and actually any non-biochemical) stimulus drive epigenetic changes in the first place is a major problem of the whole (social) epigenetic field and promises to remain an unsolved conundrum for a while. What is missing is the very first scene of this play, that is the bridge between music (or any other form of human learning, for the matter) and epigenetic modifications. One possible mode could be stochasticity, where epigenetic marks are first placed randomly in early development (creating metastable epialleles) and selected afterward by the environment (Rakyan et al., 2002; Waterland et al., 2006). Alternatively, it is tempting to ask if epigenetic enzymes placing a variety of marks 

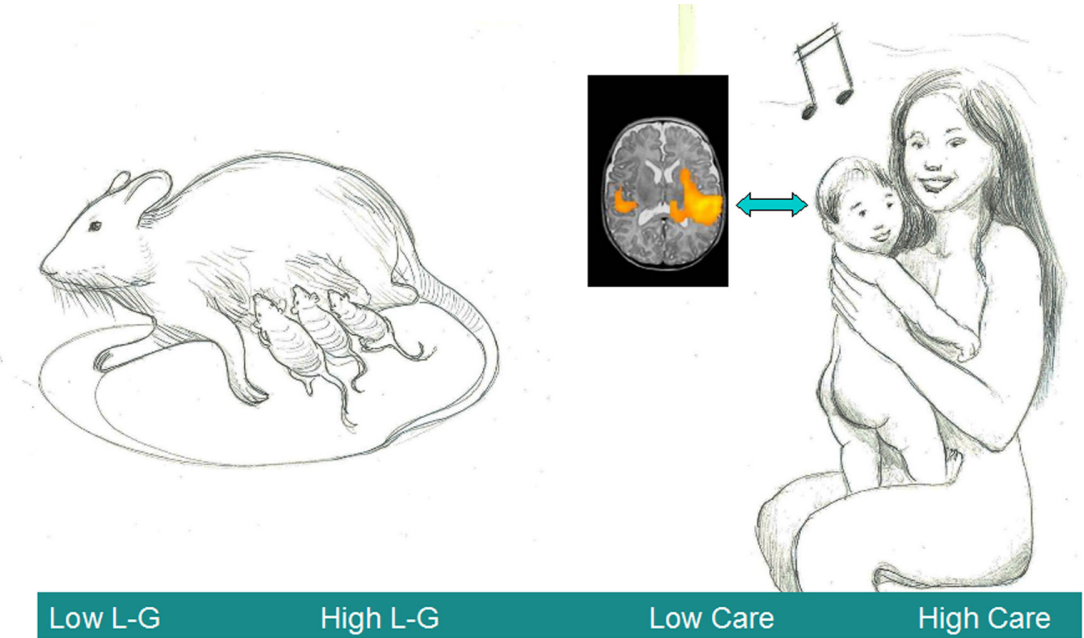

\section{tgagrggtt...cgg agtgg...cgggggcg \\ cgagcggtt...cgg agtgg...cgggggcg}

neuron-specific GR promoter

FIGURE 1 | A parallel between the maternal care scenarios in rodents and humans. Licking-grooming $(L-G)$ in rats, usually accompanying arched-back nursing, could have a human counterpart in mothers embracing their child while chanting a lullaby. The

demethylation in crucial promoters documented in rats could also occur

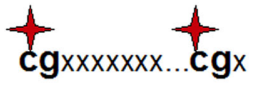

$x x x x \ldots x x x x x x x x x x$

$\operatorname{cg} x x x x x x x \ldots \operatorname{cg} x$

$x x x x \ldots x x x x x x x x x x$

\section{your favorite promoter}

in human neural circuits within defined brain areas. Inset shows. an fMRI image of newborns' such areas after musical stimulation. Note the right hemisphere predominance of temporal activation (adapted with permission from Perani et al., 2010). Stars represent methylated cytosines within $\mathrm{CpG}$ doublets.

could link social stimulations to cellular chemistry, given that some epigenetic proteins (like histone demethylases of the JMJD family and HDACs) are metal ion-dependent and an intimate connection between environmental/behavioral habits and chromatin structure has been established in cellular memory (Brasacchio et al., 2009). Obviously, his issue is still completely open to debate.

\section{MEMES RIVISITED}

In 1976 Richard Dawkins, in The Selfish Gene (Dawkins, 1976) had introduced the concept of memes, defined as: "a new kind of replicator ...staring us in the face; still in its infancy, still drifting clumsily about in its primeval soup, but achieving evolutionary change at a rate that leaves the old gene panting far behind." Dawkins describes Memes as melodies, catch phrases, ideas, insights, etc., seen as infectious particles which we use as a base to breed in our social living. In the growing branch of Memetics (Jouxtel, 2010) the rigid genetic coding lying behind the work of Ohno would be replaced by the presence of such transmissible units in our brains, behaving as selfish motors of cultural evolution. Admittedly, many questions, inherent to our discussion, remain: could neural networks endowed with epigenetic marks constitute the elusive nature of Dawkins' memes? Perhaps this nature could explain their inter-individual transmissibility, where a stored meme diffuses out, and is promptly received by others, helped by its significant affective complement. During retrieval, as in the case of music creation, these bits of information (a motif, a small melody...) would emerge strongly simply as a memory, due to their being embedded in long-term facilitated circuits. More intriguingly, could this epigenetic approach be a clue to understand musicians' self-sustained spiral compositions? Perhaps epigeneticdriven engrams were the source of the repetitive motifs found in Beethoven's fifth symphony, or in Chopin's Nocturne op. 55, N 1 (do-fa-mi-re-do-si-do-re-do, see Ohno and Ohno, 1986) or in Terry Ryley's or Steve Reich's compositions. Perhaps it is these selfsustaining, strengthening circuits that are behaviorally translated (and transmissed) in repetitive mantras, popular music riffs, great composers' obsessive units.

\section{CONCLUSION}

The Epigenetics Revolution is rapidly expanding its realms from the world of biochemistry to that of more immaterial objects, shaping the field of social epigenetics. Within this context, it would help explain how human relations influence our emerging creative minds in art and science. Music will shape our brain by depositing epigenetic marks and will induce some musicians to compose in a stereotypical or trance mode if you will, plagiarizing themselves and saying: "hey, this is my mind's I, I can do nothing about it!”. And this music will rapidly be transmitted, floating in the environment, leaving humans with a permanent, solitary gift: an epigenetic blueprint of an emotion.

\section{ACKNOWLEDGMENTS}

We are extremely grateful to the artist Lino Divinci (www.linodivinci.com) the author of the drawing depicted in Figure 1, and to P. P. Battaglin (University of Trieste, Italy) for providing helpful suggestions. 


\section{REFERENCES}

Arnsten, A. F., Ramos, B. P., Birnbaum, S. G., and Taylor, J. R. (2005). Protein kinase $\mathrm{A}$ as a therapeutic target for memory disorders: rationale and challenges. Trends Mol. Med. 11, 121-128.

Barha, C. K., Pawluski, J. L., and Galea, L. A. (2007). Maternal care affects male and female offspring working memory and stress reactivity. Physiol. Behav. 92, 939-950.

Barros, V. G., Rodriguez, P., Martijena, I. D., Perez, A., Molina, V. A., and Antonelli, M. C. (2006). Prenatal stress and early adoption effects on benzodiazepine receptors and anxiogenic behavior in the adult rat brain. Synapse 60, 609-618.

Bellet, M. M., and Sassone-Corsi, P. (2010). Mammalian circadian clock and metabolism - the epigenetic link. J. Cell Sci. 123, 3837-3848.

Borrelli, E., Nestler, E. J., Allis, C. D., and Sassone-Corsi, P. (2008). Decoding the epigenetic language of neuronal plasticity. Neuron 60, 961-974.

Branchi, I. (2009). The mouse communal nest: investigating the epigenetic influences of the early social environment on brain and behavior development. Neurosci. Biobehav. Rev. 33, 551-559.

Brasacchio, D., Okabe, J., Tikellis, C., Balcerczyk, A., George, P., Baker, E. K., Calkin, A. C., Brownlee, M., Cooper, M. E., and El-Osta, A. (2009). Hyperglycemia induces a dynamic cooperativity of histone methylase and demethylase enzymes associated with gene-activating epigenetic marks that coexist on the lysine tail. Diabetes 58, 1229-1236.

Brown, K., and Mastrianni, J. A. (2010). The prion diseases. J. Geriatr. Psychiatry Neurol. 23, 277-298.

Buchen, L. (2010). Neuroscience: in their nurture. Nature 467, 146-148.

Carter, C. S. (2005). The chemistry of child neglect: do oxytocin and vasopressin mediate the effects of early experience? Proc. Natl. Acad. Sci. U.S.A. 102, 18247-18248.

Caspi, A., Sugden, K., Moffitt, T. E., Taylor, A., Craig, I. W., Harrington, H., Mcclay, J., Mill, J., Martin, J., Braithwaite, A., and Poulton, R. (2003). Influence of life stress on depression: moderation by a polymorphism in the 5-HTT gene. Science 301, 386-389.

Champagne, F. A., Curley, J. P., Keverne, E. B., and Bateson, P. P. (2007). Natural variations in postpartum maternal care in inbred and outbred mice. Physiol. Behav. 91, 325-334.

Champagne, F. A., and Meaney, M. J. (2007). Transgenerational effects of social environment on variations in maternal care and behavioral response to novelty. Behav. Neurosci. 121, 1353-1363.

Champagne, F. A., Weaver, I. C., Diorio, J., Dymov, S., Szyf, M., and Meaney, M. J. (2006). Maternal care associated with methylation of the estrogen receptor-alphalb promoter and estrogen receptor-alpha expression in the medial preoptic area of female offspring. Endocrinology 147, 2909-2915

Chang, L., Schwartz, D., Dodge, K. A., and Mcbride-Chang, C. (2003). Harsh parenting in relation to child emotion regulation and aggression. J. Fam. Psychol. 17, 598-606.

Custers, R., and Aarts, H. (2010). The unconscious will: how the pursuit of goals operates outside of conscious awareness. Science 329, 47-50.

Dawkins, R. (1976). The Selfish Gene. Oxford: Oxford University Press

Drayna, D., Manichaikul, A., De Lange, M., Snieder, H., and Spector, T. (2001). Genetic correlates of musical pitch recognition in humans. Science 291, 1969-1972.

Edeline, J. M. (1999). Learninginduced physiological plasticity in the thalamo-cortical sensory systems: a critical evaluation of receptive field plasticity, map changes and their potential mechanisms. Prog. Neurobiol. 57, 165-224.

Eilertsen, K. J., Power, R. A., Harkins, L. L., and Misica, P. (2007). Targeting cellular memory to reprogram the epigenome, restore potential, and improve somatic cell nuclear transfer. Anim. Reprod. Sci. 98, 129-146.

Gilbert, L., Williamson, K. A., and Graves, J. A. (2012). Male attractiveness regulates daughter fecundity non-genetically via maternal investment. Proc. Biol. Sci. 279, 523-528.

Gould, E., Beylin, A., Tanapat, P., Reeves, A., and Shors, T. J. (1999). Learning enhances adult neurogenesis in the hippocampal formation. Nat. Neurosci. 2, 260-265.

Guan, Z., Giustetto, M., Lomvardas, S., Kim, J. H., Miniaci, M. C., Schwartz, J. H., Thanos, D., and Kandel, E. R. (2002). Integration of longterm-memory-related synaptic plasticity involves bidirectional regulation of gene expression and chromatin structure. Cell 111, 483-493.

Guerrero-Bosagna, C., Settles, M., Lucker, B., and Skinner, M. K. (2010). Epigenetic transgenerational actions of vinclozolin on promoter regions of the sperm epigenome. PLoS ONE 5, el3100. doi:10.1371/journal.pone.0013100
Hajkova, P., Ancelin, K., Waldmann, T., Lacoste, N., Lange, U. C., Cesari, F. Lee, C., Almouzni, G., Schneider, R. and Surani, M. A. (2008). Chromatin dynamics during epigenetic reprogramming in the mouse germ line. Nature 452, 877-881.

Hose, B., Langner, G., and Scheich, H. (1987). Topographic representation of periodicities in the forebrain of the mynah bird: one map for pitch and rhythm? Brain Res. 422, 367-373.

$\mathrm{Hu}, \mathrm{H} ., \mathrm{R}$ eal, E., Takamiya, K., Kang, M. G., Ledoux, J., Huganir, R. L., and Malinow, R. (2007). Emotion enhances learning via norepinephrine regulation of AMPA-receptor trafficking. Cell 131, 160-173.

Huang, J., Sengupta, R., Espejo, A. B. Lee, M. G., Dorsey, J. A., Richter, M., Opravil, S., Shiekhattar, R., Bedford, M. T., Jenuwein, T., and Berger, S. L. (2007). p53 is regulated by the lysine demethylase LSD1. Nature 449, 105-108.

Irvine, D. R., and Rajan, R. (1996). Injury- and use-related plasticity in the primary sensory cortex of adult mammals: possible relationship to perceptual learning. Clin. Exp. Pharmacol. Physiol. 23, 939-947.

Jabes, A., Lavenex, P. B., Amaral, D. G., and Lavenex, P. (2010). Quantitative analysis of postnatal neurogenesis and neuron number in the macaque monkey dentate gyrus. Eur. J. Neurosci. 31, 273-285.

Jacinto, F. V., Ballestar, E., and Esteller, M. (2008). Methyl-DNA immunoprecipitation (MeDIP): hunting down the DNA methylome. Biotechniques 44, 35-39.

Janata, P. (2009). The neural architecture of music-evoked autobiographical memories. Cereb. Cortex 19, 2579-2594.

Jouxtel, P. (2010). Memetics. Paris: Editions Le Pommier.

Kim, M. S., Yamashita, K., Baek, J. H., Park, H. L., Carvalho, A. L., Osada, M., Hoque, M. O. Upadhyay, S., Mori, M., Moon, C., and Sidransky, D. (2006). Nmethyl-D-aspartate receptor type $2 \mathrm{~B}$ is epigenetically inactivated and exhibits tumor-suppressive activity in human esophageal cancer. Cancer Res. 66, 3409-3418.

Koelsch, S. (2005a). Investigating emotion with music: neuroscientific approaches. Ann. N. Y. Acad. Sci. 1060, 412-418.

Koelsch, S. (2005b). Neural substrates of processing syntax and semantics in music. Curr. Opin. Neurobiol. 15, 207-212.
Koelsch, S., Fritz, T., Schulze, K., Alsop, D., and Schlaug, G. (2005). Adults and children processing music: an fMRI study. Neuroimage 25, 1068-1076.

Krupanidhi, S., Sedimbi, S. K., Vaishnav, G., Madhukar, S. S., and Sanjeevi, C. B. (2009). Diabetes - role of epigenetics, genetics, and physiological factors. Zhong Nan Da Xue Xue Bao Yi Xue Ban 34, 837-845.

Kuo, M. H., and Allis, C. D. (1998). Roles of histone acetyltransferases and deacetylases in gene regulation. Bioessays 20, 615-626.

Kuzumaki, N., Ikegami, D., Tamura, R., Hareyama, N., Imai, S., Narita, M., Torigoe, K., Niikura, K., Takeshima, H., Ando, T., Igarashi, K., Kanno, J., Ushijima, T., Suzuki, T., and Narita, M. (2011). Hippocampal epigenetic modification at the brain-derived neurotrophic factor gene induced by an enriched environment. Hippocampus 21, 127-132.

Leshem, M., and Schulkin, J. (2011). Transgenerational effects of infantile adversity and enrichment in male and female rats. Dev. Psychobiol. doi: 10.1002/dev.20592. [Epub ahead of print].

Levenson, J. M., O’Riordan, K. J., Brown, K. D., Trinh, M. A., Molfese, D. L. and Sweatt, J. D. (2004). Regulation of histone acetylation during memory formation in the hippocampus. J. Biol. Chem. 279, 40545-40559.

Levenson, J. M., and Sweatt, J. D. (2005). Epigenetic mechanisms in memory formation. Nat. Rev. Neurosci. 6, 108-118.

Levine, A. A., Guan, Z., Barco, A., Xu, S., Kandel, E. R., and Schwartz, J. H. (2005). CREB-binding protein controls response to cocaine by acetylating histones at the fosB promoter in the mouse striatum. Proc. Natl. Acad. Sci. U.S.A. 102, 19186-19191.

Liu, L., Li, Y., and Tollefsbol, T. O. (2008). Gene-environment interactions and epigenetic basis of human diseases. Curr. Issues Mol. Biol. 10, 25-36.

Lubin, F. D. (2011). Epigenetic gene regulation in the adult mammalian brain: multiple roles in memory formation. Neurobiol. Learn. Mem. 96, 68-78.

McGowan, P. O., Sasaki, A., D’Alessio, A. C., Dymov, S., Labonte, B., Szyf, M., Turecki, G., and Meaney, M. J. (2009). Epigenetic regulation of the glucocorticoid receptor in human brain associates with childhood abuse. Nat. Neurosci. 12, 342-348.

Mehler, M. F., and Mattick, J. S. (2007). Noncoding RNAs and RNA editing 
in brain development, functional diversification, and neurological disease. Physiol. Rev. 87, 799-823.

Menard, J. L., and Hakvoort, R. M. (2007). Variations of maternal care alter offspring levels of behavioural defensiveness in adulthood: evidence for a threshold model. Behav. Brain Res. 176, 302-313.

Molaro, A., Hodges, E., Fang, F., Song, Q., McCombie, W. R., Hannon, G. J., and Smith, A. D. (2011). Sperm methylation profiles reveal features of epigenetic inheritance and evolution in primates. Cell 146, 1029-1041.

Morris, C. A., and Mervis, C. B. (2000). Williams syndrome and related disorders. Annu. Rev. Genomics Hum. Genet. 1, 461-484.

Ohno, S., and Ohno, M. (1986). The all pervasive principle of repetitious recurrence governs not only coding sequence construction but also human endeavor in musical composition. Immunogenetics 24, 71-78.

Ohta, R., Shirota, M., Tohei, A., and Taya, K. (2002). Maternal behavior, milk ejection, and plasma hormones in Hatano high- and low-avoidance rats. Horm. Behav. 42, 116-125.

Patel, A. D. (2008). Science and music: talk of the tone. Nature 453, 726-727.

Perani, D., Saccuman, M. C., Scifo, P., Spada, D., Andreolli, G., Rovelli, R., Baldoli, C., and Koelsch, S. (2010). Functional specializations for music processing in the human newborn brain. Proc. Natl. Acad. Sci. U.S.A. 107, 4758-4763.

Rakyan, V. K., Blewitt, M. E., Druker, R., Preis, J. I., and Whitelaw, E. (2002). Metastable epialleles in mammals. Trends Genet. 18, 348-351.

Rakyan, V. K., Chong, S., Champ, M. E., Cuthbert, P. C., Morgan, H. D., Luu, K. V., and Whitelaw, E. (2003). Transgenerational inheritance of epigenetic states at the murine $\operatorname{Axin}(\mathrm{Fu})$ allele occurs after maternal and paternal transmission. Proc. Natl. Acad. Sci. U.S.A. 100, 2538-2543.

Reul, J. M., Hesketh, S. A., Collins, A., and Mecinas, M. G. (2009). Epigenetic mechanisms in the dentate gyrus act as a molecular switch in hippocampus-associated memory formation. Epigenetics 4, 434-439.

Rinne, T., De Kloet, E. R., Wouters, L., Goekoop, J. G., Derijk, R. H., and Van Den Brink, W. (2002). Hyperresponsiveness of hypothalamic-pituitaryadrenal axis to combined dexamethasone/corticotropinreleasing hormone challenge in female borderline personality disorder subjects with a history of sustained childhood abuse. Biol. Psychiatry 52, 1102-1112.

Si, K., Giustetto, M., Etkin, A., Hsu, R., Janisiewicz, A. M., Miniaci, M. C., Kim, J. H., Zhu, H., and Kandel, E. R. (2003). A neuronal isoform of CPEB regulates local protein synthesis and stabilizes synapse-specific long-term facilitation in Aplysia. Cell 115, 893-904.

Szyf, M., Weaver, I., and Meaney, M. (2007). Maternal care, the epigenome and phenotypic differences in behavior. Reprod. Toxicol. 24, 9-19.

Szyf, M., Weaver, I. C., Champagne, F. A., Diorio, J., and Meaney, M. J.
(2005). Maternal programming of steroid receptor expression and phenotype through DNA methylation in the rat. Front. Neuroendocrinol. 26, 139-162.

Takao, T., Culp, S. G., and De Souza, E. B. (1993). Reciprocal modulation of interleukin-1 beta (IL-1 beta) and IL-1 receptors by lipopolysaccharide (endotoxin) treatment in the mouse brain-endocrine-immune axis. Endocrinology 132, 1497-1504.

Tamura, H., Suzuki, M., Moriya, Y., Hoshino, H., Okamoto, T., Yoshida, S., Yoshino, I. (2011). Aberrant methylation of N-methyl$\mathrm{D}$-aspartate receptor type $2 \mathrm{~B}$ (NMDAR2B) in non-small cell carcinoma. BMC Cancer 11, 220. doi:10.1186/1471-2407-11-220

Trehub, S. E. (2003). The developmental origins of musicality. Nat. Neurosci. 6, 669-673.

Wan, C. Y., and Schlaug, G. (2010). Music making as a tool for promoting brain plasticity across the life span. Neuroscientist 16, 566-577.

Waterland, R. A., Dolinoy, D. C., Lin, J. R., Smith, C. A., Shi, X., and Tahiliani, K. G. (2006). Maternal methyl supplements increase offspring DNA methylation at Axin fused. Genesis 44, 401-406.

Weaver, I. C. (2007). Epigenetic programming by maternal behavior and pharmacological intervention. Nature versus nurture: let's call the whole thing off. Epigenetics 2, 22-28.

$\mathrm{Xu}, \mathrm{F}$., Cai, R., Xu, J., Zhang, J., and Sun, X. (2007). Early music exposure modifies GluR2 protein expression in rat auditory cortex and anterior cingulate cortex. Neurosci. Lett. 420, 179-183.
Ziabreva, I., Schnabel, R., and Braun, K. (2000). Parental deprivation induces N-methyl-D-aspartatereceptor upregulation in limbic brain areas of Octodon degus: protective role of the maternal call. Neural Plast. 7, 233-244.

Ziabreva, I., Schnabel, R., Poeggel, G., and Braun, K. (2003). Mother's voice "buffers" separation-induced receptor changes in the prefrontal cortex of Octodon degus. Neuroscience 119 433-441.

Conflict of Interest Statement: The authors declare that the research was conducted in the absence of any commercial or financial relationships that could be construed as a potential conflict of interest.

Received: 06 August 2011; accepted: 26 December 2011; published online: 11 January 2012.

Citation: Brigati C, Saccuman MC, Banelli B, Di Vinci A, Casciano I, Borzì L, Forlani A, Allemanni $G$ and Romani $M$ (2012) Toward an epigenetic view of our musical mind. Front. Gene. 2:111. doi: 10.3389/fgene.2011.00111

This article was submitted to Frontiers in Behavioral and Psychiatric Genetics, a specialty of Frontiers in Genetics.

Copyright (c) 2012 Brigati, Saccuman, Banelli, Di Vinci, Casciano, Borzì, Forlani, Allemanni and Romani. This is an open-access article distributed under the terms of the Creative Commons Attribution Non Commercial License, which permits non-commercial use, distribution, and reproduction in other forums, provided the original authors and source are credited. 